\title{
Insegurança perceptual e atmosferas do medo: conexões entre realismo e horror no cinema contemporâneo
}

\author{
Fernanda Sales Rocha Santos \\ Cecília Antakly de Mello \\ Universidade de São Paulo
}

\section{Resumo}

O presente artigo pretende elaborar possíveis conexões entre um realismo de viés sensório e o gênero horror, a partir da ideia de que ambos compartilham um elemento comum: a insegurança perceptual que corrobora para a apreensão de atmosferas de suspense e de medo. Operando tanto na narrativa fílmica quanto na relação direta com o espectador, a insegurança perceptual foi debatida por Thomas Elsaesser (2015), sendo brevemente relacionada com filmes do gênero horror. Gostaríamos que aprofundar essa relação, incorporando ao debate lançado pelo autor o elemento atmosférico, que surge a partir de ambientações de filmes cuja "camada sensória" está em evidência e que, ao investirem na espacialidade e em uma quebra da centralidade do olhar humano, remetem a operações já tradicionais da narrativa do horror.

\section{Palavras-chave}

Realismo dos sentidos; Horror; Cinema contemporâneo: Insegurança perceptual; Atmosfera

\section{Introdução}

O presente artigo pretende elaborar possíveis conexões entre um realismo de viés sensório e o gênero horror, a partir da ideia de que ambos compartilham um elemento comum: a insegurança perceptual que corrobora para a apreensão de atmosferas de suspense e de medo. Operando tanto na narrativa fílmica quanto na relação direta com o espectador, a insegurança perceptual foi debatida por Thomas Elsaesser (2015), sendo brevemente relacionada com filmes do gênero horror. Gostaríamos que aprofundar essa relação, incorporando ao debate lançado pelo autor o elemento atmosférico, que surge a partir de ambientações de filmes cuja "camada sensória" está em evidência e que, ao investirem na espacialidade e em uma quebra da centralidade do olhar humano, remetem a operações já tradicionais da narra- 
tiva do horror.

\section{O Realismo dos sentidos}

Existe uma semelhança estética primordialmente ligada a uma ideia tradicional de realismo, como fundamentado por Kracauer (1997) e teorizada nos ensaios de André Bazin (2014), em filmes contemporâneos de diretores de diferentes nacionalidades. $\mathrm{O}$ uso de dispositivos formais tradicionalmente ligados ao realismo cinematográfico, como filmagens em locação, o uso de atores não profissionais, de profundidade de campo e do plano-sequência, além da ambiguidade narrativa essencial, estão presentes no cinema de diretores tão diversos quanto Abbas Kiarostami, Apichatpong Weerasethakul, Carlos Reygadas, Béla Tarr, Tsai Ming-liang, Lisandro Alonso, Alexandr Sokurov, Jia Zhangke, Gus Van Sant, Pedro Costa, Lucrecia Martel, Kleber Mendonça Filho, Benjamín Naishtat, dentre outros, cujos filmes transitam entre os principais festivais de cinema do mundo nos últimos vinte anos.

No entanto, citando a lição de Bazin de que cada onda realista difere de sua anterior, Tiago de Luca (2015), dentro do contexto de estudos sobre o que tem se convencionado como slow cinema, propõe a existência de uma especificidade contemporânea no realismo destes cinemas, que é o aspecto sensório. A base do pensamento sobre realismo sensório (ou dos sentidos) está nos primórdios da teoria realista, baseada na fenomenologia, mais precisamente na ideia de que o estilo realista afeta os sentidos dos espectadores e exaltam a dimensão sensório-material da imagem.

Inspirados em Laura Marks - que em seu livro The Skin of the Film (2000) propõe um olhar e uma escuta hápticas ligadas ao envolvimento físico entre o espectador e filme - autores como De Luca (2015) e Erly Vieria Jr. (2013, 2015) advogam a favor de uma estética sensória que define esse novo pico realista no cinema mundial dos últimos vinte anos. $\mathrm{O}$ sensório pressupõe um espectador personificado capaz de se envolver para além das dimensões narrativa e emotiva que estão enraizadas no cinema de caráter predominantemente clássico, como o cinema de gênero ou hollywoodiano. É um cinema no qual o espaço, o corpo ou mesmo o ato de filmar pode se sobrepor à progressão narrativa e ao envolvimento emocional. $\mathrm{O}$ sensório, no contexto das estéticas realistas, se relaciona com a ampliação espacial e temporal de eventos cotidianos aparentemente simples e desinteressantes, ou, nos termos de Vieria Jr., microeventos:

Tal realismo, marcado pela construção narrativa através de ambiências, pela adoção de um olhar microscópico sobre o espaço-tempo cotidiano e por uma experiência afetiva pautada pela presença de uma sensorialidade multilinear e dispersiva, poderia ser encontrado em filmes realizados nas 
últimas duas décadas, por realizadores de diversas partes do planeta. (VIEIRA JUNIOR, 2013, p. 112)

Priorizar a fruição orgânica das imagens antes de um desencadeamento narrativo com sentido único e dar ênfase na interação do personagem com o espaço, não é problemática nova no cinema considerado realista. Na década de 1950, Bazin já teorizava a respeito do privilégio e ampliação de eventos ordinários no cinema, posicionando-se a favor de um cinema para além do mundo de relações causais, um cinema que capture as ambiguidades, miudezas e impossibilidades do real. São nessas reflexões elementares de Bazin que retomamos o pensamento sobre a atual orientação da captura das contradições do real por filmes de diferentes nacionalidades. Observa-se, por exemplo, o uso hiperbólico do plano-sequência (DE LUCA, 2015) em filmes de cineastas como Gus Van Sant ou Lisandro Alonso, que se prolonga sem limites, avesso a qualquer motivação dramática, afastando a experiência cinematográfica da narratividade e conduzindo-a para uma experimentação, a priori, dos sentidos. De Luca sugere que "estes cinemas realçam a realidade principalmente como um fenômeno perceptual, sensível e experiencial, criando uma irredutibilidade fenomenológica que é percebida e transmitida através da experiência sensória”. (DE LUCA, 2015, p. 73).

Assim, o realismo de viés sensório diz respeito a um discurso audiovisual de contemplação prolongada e muda da realidade (DE LUCA, 2015, p. 61), que atualiza questões caras a Bazin referentes a capturas de fragmentos do real. Com a utilização de elementos formais como o plano-sequência hiperbólico, o hiper-realismo sonoro, closes que destacam a porosidade do corpo, suspensões de ações dramáticas, dentre outros, esse realismo dissipa a interação com a narrativa em favor de uma experiência na esfera da sensorialidade: "Gostaria de afirmar que este novo pico realista no cinema mundial é definido, acima de tudo, por uma estética sensória" (DE LUCA, 2015, p. 66). Já Thomas Elsaesser pontua que

Por um lado, o novo realismo (...) encontra sua manifestação nas humanidades em geral, mas especialmente em estudos de cinema em torno de uma renovação de interesse e reinvestimento no "corpo", "nos sentidos", pele, tato, toque e na dimensão háptica, ao qual corresponde na filosofia e na neurociência evolucionária a ideia da "mente personificada". (ELSAESSER, 2015, pp. 42-43)

Na perspectiva aqui assumida, ou seja, no contexto do realismo dos sentidos, e diante de uma análise a respeito do impulso realista junto a um imaginário do cinema de horror, podemos pensar em cineastas de diferentes nacionalidades, 
mas que dividem um mesmo apreço por um olhar para as interações entre as personagens e espaço, sob o qual a tônica da insegurança - que pode também estar no enredo ou não - perceptiva, se estabelecem. Podemos citar obras de cineastas tão diversos quanto Apichatpong Weerasethakul, Carlos Reygadas, Tsai Ming-liang, Lisandro Alonso, Gus Van Sant, Lucrecia Martel, Kleber Mendonça Filho, Olivier Assayas e Benjamín Naishtat. Dadas as diferenças de estilo e de nacionalidade, todos esses cineastas possuem trabalhos com forte vínculo com a estética realista, que destacam ambiências e atmosferas, diante de grandes ambiguidades narrativas.

\section{A tônica da insegurança}

Ao falar sobre o fenômeno do novo realismo no cinema mundial, Thomas Elsaesser (2015) propõe a existência de um "marco dois da ontologia", ou uma "ontologia pós-epistemológica", que pode ser vista como um "desaparecimento gradual" ou uma "substituição" da perspectiva, tal como entendida desde o Renascimento, como forma simbólica. Segundo o autor, ocorre uma quebra da percepção cartesiana de mundo, sendo que, diante disso, o agente humano não dispõe mais de centralidade na narrativa fílmica. Não é mais sob o ponto de vista central e protagonista humano, dentro de uma noção cartesiana de espacialidade, que o discurso cinematográfico, nesse novo realismo, se estabelece. Para Elsaesser:

o novo realismo tende a engajar um ponto de vista $\mathrm{e}$ identificar um portal ou ponto de entrada que não tomam mais como certa a centralidade do agente humano, sua posição no espaço euclidiano, e suas percepções sensoriais como base de referência ou valor padrão normativo. Em vez disso, as ações da personagem, espaços narrativos e situações dramáticas desafiam a suspensão de descrença do espectador, apresentando protagonistas cuja visão do mundo é diferente, marcada pelos limites colocados nas suas faculdades físicas ou mentais. (ELSAESSER, 2015, p. 44-45)

Continuando sua análise, Elsaesser assinala a ocorrência de uma constante insegurança perceptual diante de filmes realistas contemporâneos, o que acarreta, justamente, a dúvida ontológica. No cinema contemporâneo dispõe-se em curso uma mudança cognitiva sobre o mundo diegético. Nesse sentido, Elsaesser enfatiza que não são mais ações das personagens que dão pistas para suas vidas internas, mas sim são as "coisas" que as cercam: objetos, paisagens ou a própria duração do tempo (2015, p. 48). A ênfase na percepção dos espaços, do tempo e do objetos nos filmes comentados por Elsaesser, como Casa vazia (Bin-jip, Kim ki-duk, 2004) e Vive l'amour (Ai qing wan sui, Tsai Ming-liang, 1994), se relaciona com a noção de 
que os objetos, espaços e casas assumem um tipo particular de presença com contornos fantasmagóricos. São obras cujas atmosferas, ambiências e climas se destacam. Ainda pensando na presença perturbadora das "coisas" do mundo físico e concreto dentro de alguns filmes realistas contemporâneos, Elsaesser lança: "O que é típico destes filmes é que objetos, espaços e casas assumem um tipo particular de presença ou atividade, levando-nos à convenções do filme de terror." (2015, p. 46).

Na perspectiva levantada por Thomas Elsaesser, existe a aproximação de filmes realistas das últimas décadas com filmes de terror (aqui tomamos como semelhante ao horror, como veremos a seguir), já que os segundos trabalham há muito, e constantemente, com a insegurança perceptual. Essa insegurança perceptual significa que o espectador não consegue mais "confiar" nas instâncias protagonistas, ou seja, há uma desconfiança do próprio discurso fílmico. O novo realismo parece se posicionar deste modo diante de um mundo em que a percepção humana está filosoficamente em cheque. Certamente, a insegurança do olhar humano e do discurso fílmico lançadas por Elsaesser possui resquícios de elementos do modernismo no cinema (e por isso, também, do realismo Baziniano). Trata-se, todavia, de um fenômeno pertinente ao cinema contemporâneo, vinculado com uma atualização dos preceitos modernos e muito calcado na disposição do sensório e na materialidade do real.

Talvez aqui esteja o chave fundamental de definição de um novo "ciclo" ou "tendência" na qual o horror e o realismo se aproximam e dialogam no cinema mundial. O horror sempre esteve a jogar com mudanças de percepção - especialmente se lembrarmos da literatura gótica do século XVII na qual elementos da paisagem, dos ambientes e dos climas meteorológicos adquirem presença, refletindo disposições interiores das personagens e criando tensões. Vale lembrar que o horror, no cinema, é um gênero sensório por excelência, como propõe Williams (1991). Então, parece-nos mais seguro dizer que as novas experiências realistas ligadas ao sensório evocam a falta de perspectiva ou insegurança diante de um real que, por ser inseguro, pode se assemelhar, em alguma medida, as experiências do horror.

Dos exemplos citados por Thomas Elsaesser, alguns estão bastante próximos das convenções do horror, como é o caso de Os outros (Los otros, Alejandro Amenábar, 2001) e Donnie Darko (Richard Kelly, 2001). Nesse contexto, Elsaesser destaca filmes que tratam de situações, na terminologia do autor, post-mortem: "O novo realismo ou agitação ontológica favorece o que em outra ocasião chamei de protagonista post-mortem" (2014, p. 45). Essa noção fantasmagórica do protagonista também é um ponto de conexão muito forte entre realismo e horror, como ocorre claramente nos filmes de Apichatpong Weerasethakul, Kim Ki-duk ou Lisandro Alonso. Já um filme mais recente que se encaixa precisamente na teorização de Elsaesser, e o longa-metragem Personal Shopper de Olivier Assayas (2017), que também mistura horror, realismo, quebra de perspectiva e e a temática da fantasmagoria.

Diante dessas observações, gostaríamos de propor que há no cinema 
mundial do início do século XXI uma conexão entre realismo e horror operando primordialmente pela quebra do vínculo do real com a centralidade do olhar humano, dispondo assim objetos, cenários, ambiências e climas atmosféricos em proeminência narrativa. Isso gera experiências muito sensórias, com apelo ao corpóreo e ao tátil. Essa conexão emerge substancialmente da disposição de diversos cineastas contemporâneos em explorar, através do cinema, o real do ponto de vista da insegurança (perceptual ou das personagens no enredo) e da impossibilidade de discursos totalmente transparentes ou totalmente opacos. Existe uma zona de sombra entre a opacidade e a transparência - binarismo esse já anacrônico para tratar do cinema e audiovisual contemporâneos - que parece ser explorada na atualidade. Diante de um mundo pós-moderno, o discurso cinematográfico que parece refletir o real é o da insegurança, tensão, suspense e medo perceptuais. Nem transparente, nem opaco, mas sombrio.

\section{A insegurança perceptual em tradições narrativas do horror}

O que é o horror? Apesar de sua curta e aparente simplicidade, essa pergunta dá vazão para extensos e acalorados debates e não é nosso intuito adentrar essa seara. No entanto, pensamos serem relevantes algumas considerações sobre o que vamos chamar de "narrativas de horror", com vias a esclarecer os elementos que garantem, nessa tradição, a insegurança perceptual e as atmosferas do medo, incorporadas ao realismo sensório contemporâneo. Brigid Cherry (2009), pesquisadora de gêneros e cultura popular, lançou recentemente um importante guia sobre o cinema de horror que, além de informativo, desenvolve a tese a favor do horror como o mais flexível, adaptável e duradouro de todos os gêneros. Nesse sentido, a autora identifica o horror como uma série de subgêneros e como um fenômeno presente em diferentes cinematografias, em diferentes épocas. Desta forma o horror seria um conceito aglutinador de gêneros menores e mutáveis. Seu olhar, inovador para a teoria dominante nos estudos do gênero no Brasil, e que não está isolado", supera a tradição de entender o Horror como "filmes com monstros que causam aversão e medo", como dispostos em Noel Carroll (1999) ${ }^{2}$ que evoca as definições de Tzvetan Todorov $(1980)^{3}$ sobre a literatura fantástica.

\footnotetext{
1 Ampliando a reflexão sobre a funcionalidade do horror, e pensando para além do cinema, James B. Twitchell (1985) pontua que o horror artístico não seria, em termos estritos, um gênero, mas antes, uma coleção de motivos em uma sequência previsível que garante um efeito fisiológico específico: os arrepios. Stephen Neale, por sua vez, propõe que o horror não seria apenas um gênero, mas sim vários (NEALE, 2000, p. 9).

2 Carroll localiza o horror como um fenômeno ligado ao fantástico, de modo que narrativas que provocam medo por conta de eventos naturais não seriam de horror. Assim, para Noel Carroll, o termo terror seria o mais apropriado para essas outras histórias de medo. Delimitando o horror dentro da categoria fantástico-maraviIhoso de Todorov, Noel Carroll pressupõe a existência de figuras monstruosas como essenciais a esse gênero. No entanto, não é qualquer monstro que delimita o horror, os monstros devem causar medo e aversão aos personagens, assim como aos espectadores.
}

3 O filósofo separa enredos que tratam de eventos extraordinários em categorias como "Fantástico", "Ma- 
Nessa tradição, filmes que possuem elementos visuais e formais do gênero, no entanto que não possuem monstros, são considerados filmes de terror. A respeito da divisão entre horror e terror, atualmente, nos parece mais interessante entender o horror como uma única categoria ampla capaz de conter dentro de si diversas subcategorias, estas sim ligadas às vezes ao sobrenatural, às vezes a eventos extraordinários vinculados ao real, em diferentes contextos e sob perspectivas divergentes, como proposto por Brigid Cherry: "as noções sobre o que o gênero de horror poderia ser - ou deveria ser - estão constantemente mudando, criando novas categorias conceituais para continuar a assustar o público." (CHERRY, 2009, p.4 $)^{4}$.

Não é só no horror que existem monstros. Todavia, é só no horror que existe a possibilidade de se causar medo e aversão aos personagens e ao espectador. Linda Williams (1991) sugere que o Horror é um "gênero corpóreo", capaz de causar ao espectador reações corpóreas específicas, particularmente o medo. No presente trabalho, não iremos explorar o horrífico que causa a repugnância, mas a sensação de temor diante de elementos como ambientações, atmosferas e perda de centralidade do olhar humano. S. S. Prawer (1980) separa o horror artístico em duas categorias: 1) "horrífico", definido pela emoção de medo e repugnância e 2) "estranho", definido por um sentimento de temor e um medo imaginativo. Ambas as categorias são capazes de abarcar uma numerosa série de filmes, estruturalmente diferentes, sendo que o eixo que as liga é como o espectador as recebe. Assim, ainda que não cause "arrepios" e "sustos", uma obra de horror pode ser identificada por transmitir estranheza e desconforto conectados com elementos narrativos e de estilo. Essa perspectiva sensorial sobre a apreensão, que não necessariamente é o susto, é justamente o que conecta o imaginário do horror com os filmes do realismo sensório contemporâneo.

O espaço, nas narrativas de horror, é elemento constante de tensão e medo: maldições que tornam o lugar mal-assombrado, sombras sob as quais um assassino ou um monstro podem se esconder, portas que ao serem abertas revelarão segredos terríveis, dentre outras possibilidades. $\mathrm{O}$ tempo de suspensão de ações das personagens - o famoso suspense - pode coincidir com planos de detalhamento do cenário, de objetos que ameaçam, e com a amplificação de ruídos e da trilha musical. O clima meteorológico, outro composto da atmosfera fílmica, também é elemento visual e sonoro ressaltado em momentos de suspensão de ação dramática: nuvens que fecham o céu, raios que caem, chuvas torrenciais etc. O espaço e os objetos, por vezes, tornam-se eles próprios a ameaça, ou o monstro, como nas

ravilhoso" e "Estranho", cuja definição se encontra no modo como os acontecimentos sobrenaturais são encarados (com naturalidade, com explicações racionais ou com certa ambiguidade). Em sua visão, o horror se localizaria dentro da subcategoria "Fantástico-maravilhoso" na qual os fenômenos sobrenaturais causam aversão, medo e perplexidade aos personagens.

4 Tradução nossa: “...notions of what the horror genre might be - or should be - are constantly shifting, creating new conceptual categories in order to keep on scaring the audience." (CHERRY, 2009, p. 4)" 
histórias de espaços mal-assombrados.

Como exemplo dessa situação de suspensão, por demais recorrentes nas narrativas de horror, podemos pensar no primeiro longa-metragem da franquia Atividade paranormal (Paranormal Activity, Oren Peli, 2007). Nesse filme, o apelo realista se dá no uso do dispositivo da câmera de segurança e de outras câmeras intradiegéticas sendo, também por isso, pertinente exemplo para o presente trabalho. Em longos planos-sequências da gravação de uma câmera instalada no quarto de um casal aguardamos que "algo aconteça". A imobilidade dos corpos, e a percepção de que "nada está acontecendo" pode ser por demais angustiante ao espectador que, sabendo do que se trata o filme, entende que um susto poderá acontecer a qualquer momento. Com o passar do tempo sem ação humana, começamos a reparar nos ruídos, nos estalos dos objetos. Estes, por sua vez, começam a se mover. Com o tempo, os objetos ganham presença e se incorporam na frente do olhar de outro objeto - a câmera de segurança. Até que o horror mais explicito acontece: uma sombra cruza a profundidade de campo, o cobertor da protagonista cai ao chão, ela mesma é puxada da cama, arrastada pelo chão e desaparece no corredor, em profundidade e aos gritos de socorro. Seu marido desperta. A porta do quarto bate, com violência, se fechando.

A ênfase em paradas dramáticas para ambientação e climatizações que geram o suspense da ação - além da presença, e o possível ponto de vista, de objetos não é algo novo ao horror e remonta elementos já presentes na literatura gótica do século XVIII ${ }^{5}$. Do mesmo modo, outro elemento que acreditamos ser presente em obras de horror e que ressoa características da literatura gótica europeia do século XVIII, é uma forma de narrar que confunde propositalmente o leitor/ espectador. Ou seja, o ponto de vista narrativo não é seguro e sim encoberto de contradições. Nessa perspectiva, a própria narração é algo a se desconfiar. A literatura gótica, muito antes das telas de cinema, já ameaçava a segurança, os preceitos iluministas de ordem e progresso, e própria perspectiva clássica, em relação ao conhecimento que o ser humano tem do mundo:

Textualmente o gótico se apresenta como um efeito retórico que desafia a segurança epistemológica do leitor. (...) Mas o gótico persiste, como uma semente de incerteza alojada nas fundações da razão, pronta para emergir de novo, ou penetrar raízes cada vez mais fundo, até trazer a casa inteira abaixo. (DE SÁ, 2010, p. 19)

Retomando o ponto da insegurança perceptual e quebra da perspectiva clássica, numa concepção cartesiana de mundo, debatidas por Thomas Elsaesser,

5 O espaço é um elemento central nas narrativas góticas. Em muitos casos é personificado, tornando-se ele próprio uma monstruosidade capaz de gerar seus próprios monstros" (FRANÇA, 2015: p.6) 
entendemos que os novos realismos, ao se vincularem com a suspensão da ação dramática em prol de um certo protagonismo dos espaços e dos dispositivos, se vinculam com as tortuosidades e inseguranças epistemológicas do horror e do gótico.

\section{Atmosfera: algumas definições}

Podemos dizer que existem filmes com "atmosferas de horror, contudo realistas". Porém, o que isso significa? O que é uma atmosfera de horror? Segundo Inês Gil (2005), a atmosfera de algo está necessariamente ligada à impressão sensória, ou ao afeto, que este algo causa; é, para a autora, um elemento de conexão e identificação entre corpos de um filme. A atmosfera está potencialmente em toda escolha formal fílmica (enquadramento, tipos de interpretação, relação entre os objetos etc.), se constituindo como um sistema de forças visíveis e invisíveis que, segundo a interpretação de Paulo Alberto Lanzoni (2017) sobre a pesquisa de Gil, "é caracterizada pela natureza, pelo ritmo e pelas relações envolvidas com estas forças” (p. 73). Contudo, esse sistema de forças só pode ser averiguado quando desencadeiam sensações e afetos. Nesse sentido, são as sensações e os afetos provocados em seus receptores que tornam a atmosfera perceptível, pois ela é uma expressão da relação entre o indivíduo e o mundo (LANZONI, 2017 p. 73).

Para Hans Ulrich Gumbrecht (2014), teórico literário alemão fundamental para a discussão sobre atmosferas em obras de arte, a ambiência de uma obra se liga a aspectos sólidos e concretos de determinado ambiente dentro da obra de arte. Por sua vez, o clima de uma obra diz respeito a aspectos meteorológicos ressaltados. Ambiência e clima são dois termos que fazem parte da ampla noção de atmosfera cunhada por Gumbrecht, que se relaciona fundamentalmente, assim como propõe Gil, com a percepção sensória de elementos concretos, como o ambiente físico, o clima meteorológico, a música e os sons. Ser afetado pelo clima atmosférico de um determinado ambiente é realizar um encontro muito concreto com o ambiente físico, propõe Gumbrecht (2014). Stimmung, conceito levantado e revisitado pelo teórico alemão, é um termo de difícil tradução, pois abrange diversos significados ligados a uma percepção sensória e ambiental de uma obra artística. Para Gumbrecht, ler e analisar um texto tomando em perspectiva seus aspectos ambientais/atmosféricos/climáticos seria uma forma tão válida de análise quanto os métodos propostos pelos estudos culturais e pelo desconstrucionismo, e analisaras atmosferas de uma obra seria realizar uma operação que leva em conta elementos ao mesmo tempo objetivos e subjetivos ${ }^{6}(2014)$. Como explica Paulo Lanzoni,

6 "Em inglês existem mood e climate. Mood refere-se a uma sensação interior, um estado de espírito tão privado que não pode sequer ser circunscrito com grande precisão. Climate diz respeito a alguma coisa objetiva que está em volta das pessoas e sobre elas exerce uma influência física. Só em alemão a palavra se reúne, a Stimme e a stimmen. A primeira significa "voz"; a segunda, "afinar um instrumento musical (...). Tal como é sugerido pelo afinar de um instrumento musical, os estados de espírito e as atmosferas específicas são experimentados num continuum, como escalas de música. Apresentam-se a nós como nuances que desafiam nosso poder de discernimento e de descrição, bem como o poder da linguagem para as captar". (GUMBRECHT, 2014, 
Buscando um espaço entre o desconstrucionismo e os estudos culturais no interior do campo literário, o autor investiu na Stimmung, palavra cuja tradução foi por ele metaforicamente aproximada a clima, atmosfera e ambiência, visando desenvolver a 'dimensão textual das formas que nos envolvem, que envolvem nossos corpos, enquanto realidade física' (Gumbrecht, 2014: 14) e evidenciar o continuum existente entre o corpo das obras analisadas e os afetos do leitor". (LANZONI, 2017, p.71)

Gumbrecht também relaciona o componente de sentido de Stimmung com a escuta dos sons $(2014$, p. 12). A audição é um sentido físico e, por meio dela, toma-se elementos concretos (notas musicais, sons emitidos, etc.) geradores de sensações, emoções e memórias. Grumbrecht coloca que a percepção do Stimmung ocorre na dimensão de fisicalidade, como o que ocorre com a música quando escutada:

Cada tom percebido é, sem dúvida, uma forma de realidade física (ainda que invisível) que "acontece" aos nossos corpos e que, ao mesmo tempo, os "envolve". Outra dimensão da realidade que acontece aos nossos corpos de modo semelhante é o clima atmosférico. Precisamente por isso, muitas vezes as referências à música e ao tempo atmosférico aparecem na literatura quando os textos tornam presentes - ou começam a refletir sobre os estados de espírito e as atmosferas. Ser afetado pelo som ou pelo clima atmosférico é uma das formas de experiência mais fáceis e menos intrusivas, mas é, fisicamente, um encontro (no sentido literal de estar-em-contra: confrontar) muito concreto com nosso ambiente físico. (GUMBRECHT, 2014, p.13)

Atmosferas se ligam, também, à tentativa de exteriorização de estados de espírito no ambiente físico, concreto. Nessa perspectiva, o cinema é um meio atmosférico por excelência, já que a impressão de estados de espírito (de personagens, de épocas ou paisagens) está em sua essência. Para Gumbrecht, para além das figuras ambientais e climáticas e dos sons musicais, existe a materialização e corporificação na forma da obra literária - o que envolve o ritmo, a prosódia etc. - e que configura a atmosfera sensorial de uma obra. Nesse sentido, seu entendimento se assemelha ao de Inês Gil, porém voltando-se para a literatura. Segundo o autor alemão:

Ler com a atenção voltada ao Stimmung sempre significa prestar atenção à dimensão textual das formas que nos envolvem, que envolvem nossos corpos, enquanto rea- 
lidade física - algo que consegue catalisar sensações interiores sem que questões de representação estejam necessariamente envolvidas. (GUMBRECHT, 2014, p. 14)

A ideia que Gil e Gumbrecht se alinham é a de que, ainda que seja um termo pouco utilizado (Stimmung ou atmosfera), é possível torná-lo operante na prática de análise, já que a sua presença no texto (literário ou audiovisual) ocorre em decorrência da articulação de elementos concretos. Esses elementos, no caso de Gumbrecht e na análise literária, se relacionam com a prosódia ${ }^{7}$ do texto e as imagens que este levanta. Já no caso de Inês Gil (que realiza um tipo de taxonomia das atmosferas) e no cinema, elementos como o tipo de plano e sua duração, componentes plásticos no quadro - como nevoeiros, manchas - e movimentos - tal o rastro do vento sobre um objeto - dentre outros, podem ser tomados para a análise de atmosferas concretas (como um clima meteorológico diegético) e abstratas (como o medo de uma personagem). Para Gil, clima e ambiência são elementos mais gerais e secundários que a atmosfera de um filme. Já para Gumbrecht os dois são partes que compõe intrinsicamente a noção ampla de atmosfera.

Cabe refletir sobre a diferenciação entre como planos, sons, movimentações e elementos plásticos são dispostos no filme para a produção de um sentido e, por outro lado, para a produção de sensações, e aí podemos pensar em Gil e Gumbrecht e na pesquisa de ambiências, climas e atmosferas relacionando-os com o realismo contemporâneo de caráter sensório. Assim, a atmosfera, em nosso recorte, se conecta com algo para além do sentido e mais ligado a fisicalidade, estados de espírito concretizados no espaço e outras sensorialidades articuladas. É relevante pontuar que os climas, as atmosferas e ambiência estão presentes em todo e qualquer filme. Não se pode pensar em uma obra audiovisual (e mesmo uma literária, teatral, plástica etc.) que seja desprovida de aspectos climáticos e ambientais específicos. No entanto, em nosso intuito de relacionar o cinema realista contemporâneo com o horror, temos uma importante e fundamental questão: Diante de enredos nos quais os conflitos são sutis - numa perspectiva de cinema realista - a articulação da ambientação parece ganhar preponderância no discurso fílmico, de modo que a sensação é sobressalente à trama; assim, os objetos e ambientes, como afirma Elsaesser, ganham presença, pulam para a primeira camada do filme ${ }^{8}$. Mesmo movimento ocorre em determinadas obras de horror, cuja tônica é menos o enredo e mais o processo de suspense e tensão que estes promovem.

7 Para Gumbrecht: “Mas o meu argumento é que esses tons, atmosferas e Stimmungen não existem nunca completamente independentes das componentes materiais das obras - principalmente da sua prosódia. Então, os textos afetam os 'estados de espírito' dos leitores da mesma maneira que o clima atmosférico e a música." (2014, p.14)

8 Paralelamente, na literatura, Gumbrecht volta sua atenção para o romance Morte em Veneza de Thomas Mann, afirmando categoricamente que a atmosfera do romance é tão forte que assume o primeiro plano narrativo. 
Gumbrecht ainda relaciona o Stimmung das obras literárias e a atmosfera do tempo histórico em que estas foram produzidas. Por exemplo, o autor cita $\mathrm{Me}$ morial de Aires - o diário ficcional de Machado de Assis - que, segundo o teórico, teria uma atmosfera que "nos conduz à melancolia e ao vago abandono que deve ter sido o cenário do Rio de Janeiro no tardo-império" (2014, p. 24). Relacionar o tempo histórico com a obra fílmica, não pelo sentido impresso nesta, mas antes, pela convergência de impressões sensórias entre a época que esta foi filmada e o filme, nos parece algo essencialmente vinculado ao realismo Baziniano e sua ânsia pela captura de ambientes reais. Nesse sentido, o que podemos apreender do tempo histórico desses filmes realistas que se vinculam com o sensório, com a quebra perceptual e com o horror, por meio de suspensões de ações, extensão temporal, ambiências e climas soturnos? Ainda que, segundo Gumbrecht, a análise tome a ambiência, o clima e, consequentemente, a atmosfera, vinculadas às sensações, novos sentidos podem brotar de uma segunda mirada:

A ideia de Stimmung, sempre que possível, comprova a capacidade de revelar novos aspectos do sentido. Talvez a adaptabilidade do conceito torne possível ultrapassar a sua atual irrelevância e, em configurações futuras, venha a manifestar-se um inesperado potencial para o sentido. (GUMBRECHT, 2014, p. 32)

Podem haver sentidos ocultos por trás da ambientação e climatização, contudo, uma atmosfera em si não é expressão de um sentido e surge, classicamente, como a preparação de ações. Pensando no conceito de realismo dos sentidos (De Luca, 2015) e de evidência e presença (Elsaesser, 2015) diante de filmes que dialogam com elementos caros a tradição (e invenção) do horror, usar termos como "atmosfera", "ambiência" e "clima" como figuras fílmicas para analise nos parece contundente, sendo uma possível "ponte" entre os gêneros e estilos de obras muito diferentes em seus sentidos, em suas tramas. Deste modo, esse trabalho visa propor a atmosfera como ferramenta plausível de análise fílmica, que supere os enredos e suas conexões com o extra-fílmico e, baseando-se primordialmente no estilo, traça relações inesperadas, tal como a que colocamos aqui, entre realismo dos sentidos e horror.

\section{Dois exemplos argentinos e consideração final}

Não é intuito do artigo realizar um aprofundamento na cinematografia de um cineasta, ou uma análise fílmica de uma obra especifica. No entanto, pensamos ser pertinente pontuar alguns dos diversos exemplos de onde o realismo contem- 
porâneo se vincula com o horror, em termos atmosféricos e sensoriais, levando em conta elementos como a quebra do ponto de vista central e humano, e a insegurança perceptual. Sendo assim, mencionaremos, para finalizar, trabalhos de dois cineastas argentinos que julgamos exemplares para essa possível tendência.

O filme Fantasma (2006) do argentino Lisandro Alonso trabalha com extensos planos-sequências que dão vasão à espacialidade e atmosfera de um antigo cinema enquanto um ator, o protagonista de um longa que está prestes a estrear, vaga por suas salas, a espera da hora da sessão ${ }^{9}$. A espera parece ser um tema propício as narrativas do sensório, quando os espaços e objetos marcam suas presenças. No filme de Alonso, elementos de suspensão, como os planos longos, o uso de lentíssimos travelling in e travelling out, ruídos do espaço postos em primeiro plano como um irritante e continuo alarme - trazem a concretude do espaço para frente de qualquer possibilidade de psicologia ou profundidade da personagem. Em determinado momento, diante dos ruídos do prédio, dentro de um corredor escuro, em uma sequência sem cortes, uma personagem "se arma" com uma mangueira e ameaça as paredes do próprio edifício:

Como a construção sonora de uma casa mal assombrada, essa sequência pode demonstrar que o prédio possui uma vida própria. Possui seus fantasmas. O alarme, a água, o ruído abafado do espaço vazio soam sem a necessidade da presença humana em quadro. Nesse sentido, desenvolvem um papel predominantemente autônomo. Por vezes, essa atmosfera, erguida principalmente pela construção sonora, desafia o personagem, a ponto dele empunhar uma arma imaginária em direção às paredes, ao teto, ao espaço escuro, ou seja, teoricamente, ao "vazio", ao "invisível”. (SANTOS, 2016, p. 99)

Em outros filmes de Alonso, como Jauja (2015) o elemento sobrenatural/ fantástico se intensifica, sendo possível "traçar um diálogo com o sobrenatural ou invisível em filmes como Mal dos Trópicos (Sud pralad, 2004) ou Tio Bonmee Que Pode Recordar Suas Vidas Passadas (Lung Boonmee Raluek Chat, 2010) de Apichatpong" (SANTOS, 2016, p.89). Com planos-sequências longuíssimos, temas que envolvem uma perspectiva fantasmagórica de existência, Alonso, ao nosso ver, é o exemplo mais emblemático em termos de cinema latino-americano, em termos de

9 "Em termos narrativos, o protagonista do filme é uma figura fantasmática: Argentino Vargas (nome do próprio ator), vaga tal qual um espírito por um edifício onde funciona uma sala de cinema, a sala do Teatro San Martín, para assistir a exibição do filme em que é protagonista: Los Muertos (filme de 2004 de Alonso). (...) O protagonista vaga para assistir às imagens projetadas de um passado, passado no qual ele surge como imagem, como fantasma ou memória de si mesmo." (SANTOS, 90, 2016) 
um realismo dos sentidos que recorre a elementos formais de narrativas de horror. Sendo que as questões que Elsaesser levanta sobre filmes asiáticos, cabem perfeitamente na cinematografia do argentino.

Lucrécia Martel, também argentina, por sua vez, assume uma profunda influência do cinema de horror em sua filmografia ${ }^{10}$. Obras como $O$ pântano (La ciénaga, 2001), A mulher sem cabeça (La Mujer sin cabeza, 2008) e Zama (2018), possuem elementos por vezes explícitos ao gênero, no entanto, é por meio de atmosferas muito bem elaborada, nas quais o elemento sonoro e a clima meteorológico se destacam, que o realismo sensorial e o estranhamento se conjuram em sua filmografia. Seus filmes propõem uma experiência de imersão em um real que é incômodo, estagnado e permeado por mau presságio. Martel faz um cinema reconhecidamente realista-sensório, como reconhece Viera (2015) e De Luca (2015), no entanto, a insegurança perceptiva está sempre nas camadas de seus filmes que articulam suspenses por intermédio de ruídos que incitam atmosferas meteorológicas de tempestades; planos escuros de ambientes isoladas; enquadramentos tortos ou que "cortam" partes dos corpos dos personagens, dentre outros procedimentos formais. Seus filmes dialogam com as atmosferas de suspensão e medo do horror.

A abertura, a beira da piscina, de O pântano, por exemplo, é extremamente atmosférica e sensória, pois a todo o momento intensifica-se - sonoramente e pela composição dos quadros - a ameaça da tempestade. Sendo no som abafado (por vezes parece que estamos dentro de uma piscina, com os ouvidos impedidos por uma matéria sólida, como a água), no céu escuro e repleto de nuvens que toma grande parte dos enquadramentos, ou na chuva que desagua já no fim da sequência. A tempestade em iminência confere à cena uma tensão particular, repleta de ambiguidades. Ao mesmo tempo, assim como a imagem da piscina lodacenta, a tempestade traduz todo o filme: um estado de paralisia, de espera, uma suspensão sombria. Todo o espaço e o clima meteorológico dessa sequência traduzem uma percepção sombria do real.

Nos momentos em que a atmosfera, com seus espaços, climas e objetos realistas, pula à frente da fruição do enredo, ao desencadeamento causa-consequência, e propõe suspensões que nos levam a convenções do horror, por meios de recursos formais, temos filmes sensórios. Muitas dessas vezes o "fazer nada" não significa que não há nada acontecendo, mas simplesmente que o ponto de vista não é mais o de uma personagem humana com a qual nos identificamos, mas sim um olhar amplo, que pode estar conectado com o espaço ou os objetos deste espaço que assumem uma espécie de presença - sendo, assim, uma perspectiva que gera inseguranças.

\section{Referências}

10 Ver BARRENHA (2013) 
BAZIN, André. O que é o cinema?. São Paulo: Cosac Naify, 2014.

CARROLL, Nöel. A filosofia do horror ou paradoxos do coração. Campinas: Papirus, 1999.

CHERRY, Brigid. Routledge Film Guidebooks: Horror. Nova York: Routledge, 2009. DE LUCA, Tiago. "Realismo dos Sentidos: uma tendência no cinema mundial contemporâneo”. In: MELLO, Cecília (Org.). Realismo Fantasmagórico. São Paulo: Coleção CINUSP, 2015.

DE SÁ, Daniel Serravalle. Gótico tropical: O sublime e o demoníaco em O Guarani. Salvador: EDUFBA, 2010.

ELSAESSER, Thomas. "Cinema Mundial: Realismo, Evidência, Presença". In: MELLO, Cecília (Org.). Realismo Fantasmagórico. Coleção CINUSP, 2015.

FRANÇA, Júlio. "As sombras do real: a visão de mundo gótica e as poéticas realistas”. In: CHIARA, Ana; ROCHA, Fátima Cristina Dias, (orgs.) Literatura Brasileira em Foco UI; em torno dos realismos. Rio de Janeiro: Casa Doze, 2015. (p. 133 - 146) KRACAUER, Siegfried. Theory of Filme: The Redemption of Physical Reality. Princeton: Princeton University Press, 1997.

LANZONI, Paulo Alberto. "Stimmungen tangíveis: incursões sobre as atmosferas na sala escura”. Rio de Janeiro: Revista ALCEU - n.34 - jan./jun. 2017. Pp 70 -80. MARKS, Laura U. The Skin of the Film: Intercultural Cinema, Embodiment and The Senses. Durham: Duke University Press, 2000.

NEALE, S. Genre and Hollywood, London: Routledge, 2000.

PRAWER, S. S. Caligari's Children: The Film as Tale of Terror, New York, NY: Da Capo Press, 1980.

SANTOS, Fernanda Sales Rocha. "Realismo sensório, horror e a fantasmagoria do cinema em Fantasma (Lisandro Alonso, 2006)". Movimento, São Paulo, Ed. 7, p. $88-103$, dez 2016.

TODOROV, Tzvetan. Introdução à literatura fantástica. Cidade do México: Editions du Seuil, 1980.

TWITCHELL, J. B. Dreadful Pleasures: An Anatomy of Modern Horror, Oxford: Oxford University Press, 1985.

VIEIRA JR, Erly. "Por uma exploração sensorial e afetiva do real": Esboços sobre a dimensão háptica do cinema contemporâneo. In: MELLO, Cecília (Org.). Realismo Fantasmagórico. Coleção CINUSP, 2015.

VIEIRA JUNIOR, Erly. "Paisagens Sonoras e Realismo Sensório no Cinema Mundial Contemporâneo".In: Contempoanea | comunicação e cultura - v.11 - n.03 - set-dez 2013 - p. 489-503.

WILLIAMS, Linda. Film Bodies: Gender, Genre, and Excess. In: Film Quarterly, Vol. 44, No. 4 (Summer, 1991), pp. 213. Disponível em: http://www.jstor.org/sta$\underline{\text { ble/1212758 }}$ 


\title{
Perceptual insecurities and atmospheres of fear: connections between realism and horror in contemporary cinema
}

\begin{abstract}
This article intends to elaborate connections between a sensorial realism and the Horror genre, from the idea that both share a common element: the perceptual insecurity that corroborates the apprehension of atmospheres of suspense and fear. Operating both in the film narrative and in its modes of address and reception, the perceptual insecurity was debated by Thomas Elsaesser (2015), being briefly related to films of the horror genre. We would like to deepen this relationship by incorporating into the debate launched by the author the atmospheric element that emerges from the ambiences of films whose "sensory layer" is in evidence and which, by investing in spatiality and in a break in the centrality of the human eye, refer to the traditional operations of the horror narrative.
\end{abstract}

\section{Keywords}

Realism of the senses; Horror; Contemporary cinema; Perceptual insecurity; Atmosphere.

\section{Sobre o autor}

Fernanda Sales Rocha Santos. Doutoranda do Programa de Pós-Graduação em Meios e Processos Audiovisuais da Escola de Comunicações e Artes da Universidade de São Paulo.

fer.salesrocha@gmail.com

Cecília Antakly de Mello. Docente do Programa de Pós-Graduação em Meios e Processos Audiovisuais da Escola de Comunicações e Artes da Universidade de São Paulo. Professora no Departamento de Cinema, Rádio e Televisão ECA-USP, vice-diretora do Cinusp Paulo Emílio e vice-presidente da Comissão de Relações Internacionais da ECA-USP. Doutorado em Cinema (Film Studies) pela Universidade de Londres, Reino Unido (2006).

cicamello@yahoo.co.uk 